УДК 373.167.1

\title{
РОЛЬ ИНТЕРНЕТ-ТЕХНОЛОГИЙ В ОБУЧЕНИИ ИНОСТРАННОМУ ЯЗЫКУ НА СОВРЕМЕННОМ ЭТАПЕ
}

\author{
Казачкова Юлия Александровна \\ Научный руководитель: Лубянова Марина Алексеевна \\ к.пед.н., доцент \\ ФГАОУ ВО «Южный Федеральный Университет»
}

\begin{abstract}
Аннотация: В данной статье рассматриваются возможности использования интернет-ресурсов, направленные как на формирование иноязычной коммуникативной компетенции учащихся, так и профессиональных компетенций учителей иностранного языка. Авторы дают подробную характеристику наиболее популярных образовательных ресурсов, рассматривают преимущества их применения при развитии отдельных языковых навыков и речевых умений, дают методические рекомендации учителю по их использованию на уроке иностранного языка, приводят пример формирования рече-произносительных навыков с использованием интернеттехнологий.
\end{abstract}

Ключевые слова: интернет-ресурсы, уроки английского языка, говорение, фонетика, популярные образовательные платформы.

\section{THE ROLE OF INTERNET TECHNOLOGIES IN TEACHING A FOREIGN LANGUAGE AT THE MODERN STAGE}

\section{Lubyanova Marina Alekseevna Kazachkova Yulia Aleksandrovna}

\begin{abstract}
This article examines the possibilities of using Internet resources aimed at both the formation of foreign language communicative competence of students and the professional competence of teachers of a foreign language. The authors give a detailed description of the most popular educational resources, consider the advantages of their use in the development of individual language and speech skills, give methodological recommendations to the teacher on their use in a foreign language lesson, give an example of the formation of speech-pronunciation skills using Internet technologies.
\end{abstract}

Key words: Internet resources, English lessons, speaking, phonetics, popular educational platforms. 
В современных условиях глобализации общества и активного внедрения новых технологий во все сферы социальной деятельности, в том числе науку и образование, в системе образования Российской Федерации проводятся работы по интеграции коммуникационных технологий, научно-методического обеспечения учебного процесса и научных исследований с целью объединить наработки системы образования с новейшими информационными технологиями, что вызвано желанием сформировать в России открытое образовательное пространство, доступное для широких слоев населения.

Применение интернет-технологий в преподавании иностранного языка необходимое условие модернизации образования на современном этапе, способствующее совершенствованию практических умений и навыков; повышению эффективности самостоятельной работы учащихся и индивидуализации процесса обучения; развитию интереса к овладению иностранным языком, активизации познавательной деятельности учащихся.

Среди объективных причин использовать ИКТ на уроках иностранного языка выделяются следующие дидактические возможности данных технологий:

- создание условий для активного, творческого овладения обучающимися изучаемым предметом, что способствует развитию коммуникативных умений;

- обеспечение условий для преподавателя изложить учебный материал на новом качественно высоком уровне, что способствует увеличению эффективности познания;

- организация учебного процесса и самостоятельной познавательной деятельности обучающихся на принципиально новом уровне, что способствует повышению мотивации, созданию положительной эмоциональной атмосферы и развитию творческого потенциала.

Внедрение интернет-технологий в учебный процесс необходимо начинать с подготовки учителя. При этом компетентность учителя иностранного языка тесно связана с информационно-коммуникативнымными технологиями (ИКТ), поскольку основная цель профессиональной деятельности - формирование у учащихся иноязычной коммуникативной компетенции.

Под компетентностью учителя иностранного языка в области ИКТ мы, вслед за И.Г. Никитенко, подразумеваем «совокупность теоретических знаний о современных информационных и коммуникационных технологиях и практических умений, использовать учебные Интернет-ресурсы, социальные сервисы Веб 2.0 и другие ИКТ в процессе формирования языковых навыков и 
развития речевых умений» [3, с.17] обучающихся при обучении иноязычному общению и культуре страны изучаемого языка. Иными словами, структура компетентности в области ИКТ состоит из теоретических знаний - владения расширенной информацией о содержании и обучающих возможностях ИКТ и практических навыков использования ИКТ в учебном процессе.

Сформированность практической составляющей компетентности предполагает развитие следующих навыков:

- применять известные и широко используемые Интернет-технологии на уроке, что способствует повышению мотивации обучающихся изучать иностранный язык;

- выводить значительный объем изучаемого материала во внеаудиторную форму работы, что представляется актуальным при сокращении часов на иностранный язык и дистанционной форме обучения;

- реализовывать на практике педагогическую технологию «обучение в сотрудничестве»;

- развивать умение самостоятельной учебной деятельности посредством ИКТ, необходимых для самообразования на протяжении всей жизни [7, с.27]

Развитие теоретической составляющей компетентности в области ИКТ предполагает знание содержания существующих специализированных сайтов, а также их функций, направленных на повышение эффективности обучения иноязычному общению.

Назовем лишь несколько из таких «палочек-выручалочек» для учителей:

1. https://www.thoughtco.com/. На данном сайте можно найти как клише для составления самых простых диалогов, так и лексика, видео и аудио для общения в различных ситуациях.

2. сервис LearningApps.org. Данный сервис позволяет создавать интерактивные модули с заданиями по пройденным темам, что поможет сделать процесс обучения и контроля более интересным и эффективным.

3. сайт www.voicethread.com или www.voxopop.com. Данные ресурсы представляют собой платформы, предназначенные для создания мультимедийных проектов. На первом сайте учитель совместно с учащимися могут загружать на данный сайт различные иллюстрации, презентации, школьные проекты и получать видео, аудио или письменные комментарии. Данные сайты помогают учащимся использовать изучаемый язык в реальном мире, непосредственно общаясь с другими людьми, а не отвечая на вопросы учебника [5, с. 20]. 
Использовать сайты www.voicethread.com или www.voxopop.com можно в следующих видах деятельности на уроках:

- создание слайд-шоу и презентаций PowerPoint и составление монологического высказывания по нему

- описание картинок на определенную тематику, которые выставлены на сайте

- составление пересказа к текстам, которые опубликовал учитель или учащиеся [5, С. 22].

4. платформа Voxорор. Аудио-форум, направленный на общение на различные темы между людьми из разных стран. Данный ресурс позволяет учащимся участвовать в различных обсуждениях, тем самым тренируя свой навык говорения и преодоление языкового барьера [4, с. 7]. Упражнения, которые можно выполнять на этой платформе схожи с предыдущими, но сюда можно добавить фонетические задания, обсуждение различных проблем, ответы на вопросы реальных людей.

5. сайт http://www.speak-english-today.com/, который помогает найти собеседника для разговоров на английском языке. Данная платформа позволяет выбрать любого человека: начиная от простых учащихся иностранных школ, заканчивая преподавателями английского языка. Именно данный вид деятельности поможет учащимся перешагнуть языковой барьер и общаться на интересные им темы. В дополнение к индивидуальному использованию этого сайта, учитель может устраивать конференции на самом уроке английского языка.

В результате работы с данными ресурсами учитель может повысить мотивацию обучающихся к познавательной деятельности, так как учащиеся увидят практическое применение изучаемого языка. Помимо этого, используя возможности сети Интернет на уроках, учитель вовлекает в образовательный процесс абсолютно каждого учащегося, тренируя не только навыки говорения, но и ИКТ грамотность обучаемых

ИКТ также является незаменимым средством организации проектной деятельности обучаемых. Например, обучающиеся выполняют свои проекты в форме презентации, затем представляют своим сверстникам данную презентацию. Выполняя творческие проектные работы, учащиеся развивают самостоятельность, творчество, активность, но самое главное - речь.

К каждой линии учебника прилагается электронное приложение АВВYY Lingvo Tutor, включающее аудиокурс для самостоятельных занятий дома, 
список треков к аудиокурсу, учебные словари ABBYY Lingvo, учебно-игровую программу для быстрого запоминания слов. Электронные приложения имеют множество преимуществ для изучения английского языка:

- мгновенный доступ к словарям;

- при установке приложения браузер Mozilla при чтении сайтов и сервисов на английском языке также предлагает мгновенный перевод слова при наведении на него курсора;

- при установке приложения компьютер через какое-то определенное время напоминает обучающемуся о том, что пора вспомнить новые лексические единицы и повторить старые;

- в приложении содержатся различные упражнения, позволяющие закрепить пройденный материал.

Применять компьютерные технологии можно не выходя в сеть Интернет. Для этого достаточно приобрести обучающие диски, которые разные фирмы производят в больших количествах.

Использование приложений обеспечивает комплексное развитие языковых и речевых компетенций учащихся, вызывает положительные эмоции при «общении» персонажем обучающей игры - Бобром.

Приведем пример использования ИКТ для развития речевых фонетических навыков.

Произношение имеет большое значение при изучении иностранного языка, поскольку его эффективность значительно определяет успех в овладении навыками устной речи. Одним из важнейших условий формирования фонетических навыков является развитие слухо-произносительных навыков, то есть правильная ассоциация слышимого звука с соответствующим ему значением и воспроизведение звука с соответствующим определенным значением.

Использование ИКТ при формировании рече-произносительных навыков имеет ряд преимуществ:

- аутентичность заданий, т.е. заданий, которые соответствуют коммуникативной задаче, встречающейся в жизни носителей языка.

- развитие межпредметных навыков использования иностранного языка в реальной жизни.

- дистанционная форма контроля, но в реальном времени, что позволяет обучающемуся технично подходить к выполнению заданий. Кроме того, мотивация обучающегося поднимается благодаря мультимедийности предлагаемых материалов и креативности заданий с ними. 
Для развития фонетических речевых навыков широко используется в российском образовании программа «Профессор Хиггинс». Она разработана российской компанией «ИстраСофт» и озвучена носителем языка. Эта программа дает обучаемым возможность в интерактивном режиме сравнить свое произношение с эталонным.

На первом этапе ознакомления с вариацией использования ЭОР в сети Интернет и подбора необходимого материала использование ИКТ-технологий позволяет наглядно продемонстрировать правила артикуляции звуков английского языка на примере носителей английского языка, что представляется достаточно сложным, используя исключительно картинки и описания в учебных пособиях. Информация, которая будет представлена в наглядной форме, является наиболее доступной для восприятия, усваивается легче и быстрее. Кроме того, использование электронного ресурса на занятиях помогает удовлетворить запросы, желания и интересы учащихся.

Второй этап предполагает использование в ЭОР как информации в напечатанном виде, так и просмотр видео, прослушивание аудио и выполнение заданий являются очень действенными методами, так как учащиеся визуализируют изученные правила и могут их сразу же применить на практике, качественно отработать разобранные интонационные модели, доведя их до автоматизма воспроизведения, и, как результат, отправить преподавателю, чтобы он сказал, определить степень успешности выполнения задания и в верном ли направлении происходит процесс изучения языка; работа с ЭОР также повышает мотивацию и вносит разнообразие в рутинную работу с теоретическим курсом по иностранному языку.

Данные приемы и методы считаются наиболее полезными, потому что формируют и поддерживают фонетические навыки, а также благотворно влияют на формирование познавательной активности учеников.

Таким образом, на сегодняшний день преподаватель иностранного языка должен уметь хорошо ориентироваться в огромном количестве Интернетресурсов, которые, обеспечивают овладение иностранным языком в единстве с культурой его носителей, а также в значительной степени облегчают работу, повышают эффективность обучения, позволяют улучшить качество преподавания. Применение ИКТ и Интернет-ресурсов на уроках английского языка дает возможность достичь стабильных положительных результатов и позволяет вести преподавание в разноуровневых классах: общеобразовательных, лицейских, с углубленным изучением английского 
языка - и достигать хорошего результата. Кроме того, использование ИКТ и Интернет-ресурсов на уроке английского языка актуально на сегодняшний день, т.к. учитель должен быть интересным для своих учеников, идти в ногу со временем, повышать свое педагогическое мастерство и уровень интеллекта

\section{Список литературы}

1. Гез И.И, Ляховицкий, М.В., Миролюбов, А.А. Методика обучения иностранным языкам в средней школе. - М.: Просвещение, 1982. - 412 с.

2. Дубень Е.А. Использование современных информационных технологий при обучении иностранному языку // Иностранные языки в школе. - 2016. - № 1. - С. 45-50.

3. Никитенко, С. Г. Интернет для учителей иностранного. - М.: Кнорус, 2002. -51 c.

4. Орлова О.Ю. Фонетические средства выразительности в языке и тексте: существующие подходы и перспективы исследования // Вестник Пермского Университета. Российская и зарубежная филология. - 2013. - № 3 (23). - C. 7-9

5. Писаренко, В.И. Использование компьютерных технологий в обучении иностранным языкам // Открытое образование, 2004. - №1. С. 17-22.

6. Подопригорова Л.А. Использование Интернета в обучении иностранным языкам // Иностранный язык в школе. - 2003.- №. С. 13-17.

7. Полилова Т.А. Внедрение компьютерных технологий / Иностранный язык в школе. - 1997. - №6. - С. 27-32.

8. Электронный pecypc "Abby" https://www.abbyy.com/ru/ (дата обращения: 07.03.2021)

9. Электронный pecypc "LearningApps" https://learningapps.org/ (дата обращения: 07.03.2021)

10. Электронный pecypc "Speak English Today" http://www.speak-englishtoday.com (дата обращения: 07.03.2021)

11. Электронный pecypc "ThougtCo" https://www.thoughtco.com/ (дата обращения: 07.03.2021)

12. Электронный pecypc "VoiceThread" www.voicethread.com (дата обращения: 07.03.2021)

13. Электронный ресурс "Voxopop" www.voxopop.com (дата обращения: $07.03 .2021)$ 